\title{
Schistosoma mansoni and Soil Transmitted Helminth (STH) Infections among Pregnant Women Attending Primary Health Care Facilities in Lagos Mainland, Nigeria
}

\author{
Babatunde Adewale1 ${ }^{*}$, Olalekan Rahaman², Oluwagbenga Aina ${ }^{3}$, Medinat A. Sulyman' \\ ${ }^{1}$ Public Health and Epidemiology Department, Nigerian Institute of Medical Research, Lagos, Nigeria \\ ${ }^{2}$ Zoology Department, University of Lagos, Lagos, Nigeria \\ ${ }^{3}$ Biochemistry and Nutrition Department, Nigerian Institute of Medical Research, Lagos, Nigeria \\ Email: ^badewale@hotmail.com
}

How to cite this paper: Adewale, B., Rahaman, O., Aina, O. and Sulyman, M.A. (2018) Schistosoma mansoni and Soil Transmitted Helminth (STH) Infections among Pregnant Women Attending Primary Health Care Facilities in Lagos Mainland, Nigeria. Journal of Biosciences and Medicines, 6, 64-70.

https://doi.org/10.4236/jbm.2018.612006

Received: May 25, 2018

Accepted: December 10, 2018

Published: December 13, 2018

Copyright $\odot 2018$ by authors and Scientific Research Publishing Inc. This work is licensed under the Creative Commons Attribution International License (CC BY 4.0).

http://creativecommons.org/licenses/by/4.0/

\begin{abstract}
In a cross-sectional survey among consented pregnant women, rapid diagnostic test (RDT) for malaria was carried out and stool examination was done to detect the presence of Schistosoma mansoni and soil transmitted helminthes using Kato-Katz technique. Intensity of infection was expressed as the number of eggs per gram (epg) of faeces. Prevalence of soil transmitted helminthes was $8.3 \%$ and $0.83 \%$ for Schistosoma mansoni while none was positive for malaria infection. Lack of co-infection with malaria could be connected with the intermittent preventive treatment with sulphadoxine pyrimethamine (IPTp-SP). Public health impact of soil transmitted helminthes and schistosomiasis infections in pregnancy may necessitate initiation of preventive treatment of helminth infections during pregnancy.
\end{abstract}

\section{Keywords}

Pregnancy, Schistosoma mansoni, Soil Transmitted Helmiths, Malaria

\section{Introduction}

Approximately $85 \%$ of the Neglected Tropical Diseases (NTD) disease burden results from helminth infections. Targeted control on school children is often advocated and is usually the main operation in sub-saharan Africa due to limited resources. However, exclusion of other groups, oftentimes comprising the adult population, makes re-infection almost inevitable in low resource rural endemic regions of the developing countries. These neglected groups (pregnant women 
are inclusive) which are believed not to be sufficiently exposed to infection and often left untreated could serve as reservoirs of infection, bringing the distribution of the disease to pre-control level over time [1]. Hookworm infection occurs in almost half of Sub-saharan Africa's poorest people, including 40 - 50 million school-aged children and 7 million pregnant women in whom it is a leading cause of anaemia. Schistosomiasis is the second most prevalent NTD after hookworm [2]. An estimated 40 million women of child bearing age suffer from schistosomiasis [3] while recent estimates suggest that 819 million people worldwide are infected with $A$. lumbricoides, 465 million with $T$. trichiura, and 439 million with hookworm [4]. The risk of the individuals suffering from Soil Transmitted Helminth (STH) infection related morbidity appears to be a joint function of the number of species harboured and/or the infection intensity of any species [5]. Therefore the significance of co-infection of Schistosoma mansoni and soil transmitted helminthes in developing countries cannot but be emphasized taking into cognizance the significant morbidities attributed to these infections which include malnutrition, growth retardation, anaemia, vitamin A deficiency, and impaired intellectual performance [6]. This is even more among the vulnerable population such as pregnant women with suppressed immunity due to their pregnancy status. A number of studies have highlighted the significance of co-infection among different strata of the population but there are limited available epidemiological data on pregnant women. This study assessed the prevalence of these infections among pregnant women in Lagos.

\section{Materials and Methods}

A cross-sectional survey was carried from June to October 2016 at two Primary Health Care facilities located in Lagos Mainland Local Government Area, Lagos, Nigeria. Consented pregnant women were recruited and semi-structured questionnaires were administered to the pregnant women to obtain demographic and risk factors information. Rapid diagnostic test (RDT) for malaria (SD BIOLINE Malaria Ag P.f/Pan) was carried out for each pregnant woman. Thick and thin blood smear were done on same slide for those that were positive by RDT. Blood was also collected into heparinized capillary tubes for the estimation of packed cell volume (PCV). Stool examination for the presence or absence of Schistosoma mansoni and soil transmitted helminthes was carried out using Kato-Katz technique. The intensity of infection of the species of worms was expressed as the number of eggs per gram (epg) of faeces. The required sample size for this study was calculated based on $95 \%$ confidence level and 5\% marginal error. Sample size $(n)$ was determined using the formular as described by Araoye [7], $n=\frac{Z^{2} P(1-P)}{D^{2}}$.

The questionnaire which was developed and pilot tested had 31 questions in 4 sections which were the socio-demographic section, knowledge of soil transmitted helminthes infection, risk factors of soil transmitted helminthes, and knowledge of malaria infection. Knowledge of risk factors include the following 
among others: questions on hand washing, type of toilet, questions on footwear usage and use of footwear when going to the toilet.

Statistical analysis was done using SPSS version 22 for windows. Descriptive statistics was employed for the analysis of demographic data. Estimation of prevalence and intensity of STH was calculated based on the stool. Chi-square was carried out to investigate the relationship between anemia and occurrence of parasitic infection in the study.

\section{Ethics Statement}

The study protocol was reviewed and approved by the Institutional Review Board of Nigerian Institute of Medical Research. The study was conducted in accordance with the tenets of Helsinki Declaration of 1964 as amended in 2013 and guidelines of Good Clinical Practice.

\section{Results}

The prevalence of soil transmitted helminthes among the 120 pregnant women examined was $8.3 \%$ (10) for soil transmitted helminthes (A. lumbricoides-7.5\% (9); Hookworm-(1) $0.83 \%$ ) and $0.83 \%$ (1) for Schistosoma mansoni while none was positive for malaria infection. There was no statistically significant difference $(\mathrm{P}=0.67)$ in the infection rate of the various age groups examined, though age group 37 - 42 had no infection. The infection rate was not related to the education of participants $(\mathrm{P}=0.168)$ (Table 1$)$. Only $40 \%$ of the pregnant women had knowledge of soil transmitted helminthes out of which $8.3 \%$ were positive for infection. There was no significant association between knowledge of soil transmitted helminthes and infection among pregnant women. Of those walking bare footed and using shared toilet facilities, $60 \%$ and $12.8 \%$ were infected respectively (Table 2). Despite the fact that all the infected pregnant women with STH had light infection, $50 \%$ of them were anaemic which occurred in all age groups except $37-42$ years age group while the only $S$. mansoni infected pregnant woman had moderate infection and was also anaemic. Anaemia was significantly associated with infection in pregnant women $(\mathrm{P}<0.05)$ (Table 3$)$.

\section{Discussion}

Ascaris lumbricoides was the most common soil transmitted helminth infection recorded in this study. This might be attributed to the ability of a single worm to release up to 200,000 eggs per day coupled with the resistant nature of the eggs which have protective proteinous coats to extreme environmental conditions. The high proportion of infected women who engaged in the risk factor of walking barefooted to the toilets could be related to the low knowledge of the women concerning soil transmitted helminthes infection. The lack of co-infection of malaria and STH among pregnant women could be related to the intermittent preventive treatment with sulphadoxine pyrimethamine (IPTp-SP) which is a policy in all government health facilities as recommended by WHO in areas of 
moderate to high malaria transmission in Africa [8] [9]. Though, A. lumbricoides infections are commonly asymptomatic, clinical complications of extra-intestinal or high numbers of ascarids have been well described [10]. The presence of hookworm and Ascaris lumbricoides infections could be responsible for blood loss as observed by van Ejik et al. [11] in Kenya and therefore soil transmitted helminthes could be regarded as a major cause of anaemia in these pregnant women having ruled out malaria infection using RDT. Also the anaemia observed in the only pregnant woman with moderate Schistosoma mansoni infection according to WHO [12] could be buttressed by other studies that evaluated the association of $S$. mansoni with pregnancy outcomes which have demonstrated an increased risk for anaemia, preterm deliveries, and low birth weight infants [3]. The significant statistical relationship between light A. lumbricoides infection and mild anaemia was consistent with the findings of Larocque et al., [13] in Peru.

Table 1. Association of STH infection with socio-demographic characteristics among Pregnant Women Attending Primary Health Care Facilities in Lagos Mainland.

\begin{tabular}{|c|c|c|c|c|}
\hline Characteristics & Number (n) & STH infection $\mathrm{n}(\%)$ & $\mathrm{X}^{2}$ & P-value \\
\hline \multicolumn{5}{|l|}{ Age groups } \\
\hline $18-24$ & 31 & $5(16.1 \%)$ & & \\
\hline $25-30$ & 56 & $4(16.0 \%)$ & 6.69 & 0.678 \\
\hline $31-36$ & 23 & $1(4.2 \%)$ & & \\
\hline $37-42$ & 10 & $0(0.0 \%)$ & & \\
\hline \multicolumn{5}{|l|}{ Education } \\
\hline No education & 2 & $0(0.0 \%)$ & & \\
\hline Primary school & 16 & $4(26.7 \%)$ & 13.59 & 0.168 \\
\hline Secondary school & 79 & $5(6.3 \%)$ & & \\
\hline Tertiary institution & 23 & $1(4.2 \%)$ & & \\
\hline \multicolumn{5}{|l|}{ Marital status } \\
\hline Never married & 6 & $1(16.7 \%)$ & 0.852 & 0.837 \\
\hline Married & 114 & $9(7.9 \%)$ & & \\
\hline \multicolumn{5}{|l|}{ Ethnicity } \\
\hline Yoruba & 97 & $9(9.3 \%)$ & & \\
\hline Hausa & 5 & $0(0.0 \%)$ & 30.15 & $0.000^{* *}$ \\
\hline Igbo & 14 & $1(7.1 \%)$ & & \\
\hline Others & 4 & $0(0.0 \%)$ & & \\
\hline \multicolumn{5}{|l|}{ Religion } \\
\hline Islam & 66 & $4(6.0 \%)$ & 4.07 & 0.272 \\
\hline Christian & 54 & $6(11.3 \%)$ & & \\
\hline \multicolumn{5}{|l|}{ Occupation } \\
\hline Unemployed & 24 & $0(0.0 \%)$ & & \\
\hline Trader & 48 & $2(4.2 \%)$ & & \\
\hline Artisan & 19 & $4(21.0 \%)$ & 20.43 & 0.156 \\
\hline Civil servant & 5 & $1(20.0 \%)$ & & \\
\hline Private employment & 22 & $2(9.1 \%)$ & & \\
\hline Others & 2 & $1(50.0 \%)$ & & \\
\hline
\end{tabular}

${ }^{* *}$ Highly significant $(\mathrm{P}<0.001)$. 
Table 2. Association of STH infection with risk factors among pregnant women.

\begin{tabular}{|c|c|c|c|c|}
\hline Characteristics & Number (n) & STH infection $\mathrm{n}(\%)$ & $\mathrm{X}^{2}$ & P-value \\
\hline \multicolumn{5}{|c|}{ Have you heard about STH } \\
\hline Yes & 48 & $4(8.3 \%)$ & 2.26 & 0.521 \\
\hline No & 72 & $6(8.3 \%)$ & & \\
\hline \multicolumn{5}{|l|}{ Place of defecation } \\
\hline Own Pit latrines & 3 & $0(0.0 \%)$ & & \\
\hline Own Flush toilet & 70 & $5(7.1 \%)$ & & \\
\hline Shared flush toilet & 39 & $5(12.8 \%)$ & 4.19 & 0.997 \\
\hline Bush/Field & 1 & $0(0.0 \%)$ & & \\
\hline Shared pit latrine & 3 & $0(0.0 \%)$ & & \\
\hline Elsewhere & 4 & $0(0.0 \%)$ & & \\
\hline \multicolumn{5}{|l|}{ Footwear in the toilet } \\
\hline Yes & 109 & $7(6.4 \%)$ & 17.31 & $0.001^{* *}$ \\
\hline No & 11 & $3(27.3 \%)$ & & \\
\hline \multicolumn{5}{|l|}{ Water source } \\
\hline Well & 4 & $0(0.0 \%)$ & & \\
\hline Tap water & 111 & $9(8.1 \%)$ & 1.62 & 0.951 \\
\hline Water from vendors & 5 & $1(20.0 \%)$ & & \\
\hline \multicolumn{5}{|l|}{ Water treatment } \\
\hline Yes & 20 & $0(0.0 \%)$ & 2.42 & 0.490 \\
\hline No & 100 & $10(10.0 \%)$ & & \\
\hline \multicolumn{5}{|l|}{ Handwashing } \\
\hline Yes & 110 & $10(9.1 \%)$ & 1.10 & 0.777 \\
\hline No & 10 & $0(0.0 \%)$ & & \\
\hline \multicolumn{5}{|c|}{ Habit of walking barefoot } \\
\hline Yes & 5 & $3(60.0 \%)$ & 56.23 & $0.000^{* *}$ \\
\hline No & 115 & $7(6.9 \%)$ & & \\
\hline \multicolumn{5}{|l|}{ Floor material } \\
\hline Earth & 2 & $0(0.0 \%)$ & & \\
\hline Cement & 28 & $1(3.6 \%)$ & 1.77 & 0.939 \\
\hline Tiles & 90 & $9(10.0 \%)$ & & \\
\hline
\end{tabular}

${ }^{*}$ Highly significant $(\mathrm{P} \leq 0.001)$.

Table 3. Association of anaemia with soil transmitted helminths infection.

\begin{tabular}{ccccc}
\hline Variable & $\mathbf{n}$ & Anaemic & $\mathbf{X}^{2}$ & P-value \\
\hline STH Infection: & & & & \\
A. lumbricoides & 9 & 4 & 61.23 & $0.000^{\star *}$ \\
Hookworm & 1 & 1 & & \\
\hline
\end{tabular}

${ }^{* *}$ Highly significant $(\mathrm{P}<0.001)$.

\section{Conclusion}

This finding confirms the public health impact of soil transmitted helminthes and schistosomiasis infections in pregnancy. This may necessitate initiation of preventive treatment of helminth infections during pregnancy.

\section{Acknowledgements}

The authors appreciate the assistance of all the nurses at the Health facilities as well as the Medical officer-in-charge of Lagos Mainland Local Government 
Area. The cooperation of all the participants is hereby acknowledged.

\section{Conflicts of Interest}

The authors declare no conflicts of interest regarding the publication of this paper.

\section{References}

[1] Salawu, O.T. and Odaibo, A.B. (2014) Maternal Schistosomiasis: A Growing Concern in Sub-Saharan Africa. Pathogens and Global Health, 108, 263-270. https://doi.org/10.1179/2047773214Y.0000000150

[2] Hotez, P.J. and Kamath, A. (2009) Neglected Tropical Diseases in Sub-Saharan Africa: Review of Their Prevalence, Distribution, and Disease Burden. PLOS Neglected Tropical Diseases, 3, e412. https://doi.org/10.1371/journal.pntd.0000412

[3] Mombo-Ngoma, G., Honkpehedji, J., Basra, A., Mackanga, J.R., Zoleko, R.M., Zinsou, J., Agobe, J.C.D., Bertrand Lell, B., Matsiegui, P.B., Gonzales, R., Agnandji, S.T., Yazdanbakhsh, M., Menendez, C., Kremsner, P.G., Adegnika, A.A. and Ramharter, M. (2017) Urogenital Schistosomiasis during Pregnancy Is Associated with Low Birth Weight Delivery: Analysis of a Prospective Cohort of Pregnant Women and Their Offspring in Gabon. International Journal for Parasitology, 47, 69-74. https://doi.org/10.1016/j.ijpara.2016.11.001

[4] Pullan, R.L., Smith, J.L., Jasrasaria, R. and Brooker, S.J. (2014) Global Numbers of Infection and Disease Burden of Soil Transmitted Helminth Infections in 2010. Parasites \& Vectors, 7, 37. https://doi.org/10.1186/1756-3305-7-37

[5] Hurlimann, E., Yapi, R.B., Houngbedji, C.A., Schmidin, T., Kuadio, B.A., Silue, K.D., Quattara, M., N'Goran, E.K., Utzinger, J. and Raso, G. (2014) The Epidemiology of Polyparasitism and Implications for Morbidity in Two Rural Communities of Cote d'Ivoire. Parasite Vectors, 7, 81. https://doi.org/10.1186/1756-3305-7-81

[6] Adegnika, A.A., Ramharter, M., Agnandji, S.T., Ngoa, U.A., Issifou, S., Yazdanbahksh, M, and Kremsner, P.G. (2010) Epidemiology of Parasitic Co-Infections during Pregnancy in Lambarene, Gabon. Tropical Medicine \& International Health, 15, 1204-1209. https://doi.org/10.1111/j.1365-3156.2010.02598.x

[7] Araoye, M.O. (2004) Sample Size Determination in Research Methodology with Statistics for Health and Social Sciences. Nathadex Publishers, Ilorin, 115-121.

[8] World Health Organization (2004) A Strategic Framework for Malaria Prevention and Control during Pregnancy in the African Region. World Health Organization, Regional Office for Africa, Brazzaville.

[9] Agomo, C.O., Oyibo, W.A. and Odukoya-Maije, F. (2011) Parasitologic Assessment of Two-Dose and Monthly Intermittent Preventive Treatment of Malaria during Pregnancy with Sulphadoxine-Pyremethamine (IPTP-SP) in Lagos, Nigeria. Malaria Research and Treatment, 2011, 932895. https://doi.org/10.4061/2011/932895

[10] Holcombe, C. (1995) Surgical Emergencies in Tropical Gastroenterology. Gut, 36, 9-11. https://doi.org/10.1136/gut.36.1.9

[11] van Eijk, A.M., Lindblade, K.A., Odhiambo, F., Peterson, E., Rosen, D.H., et al. (2009) Geohelminth Infections among Pregnant Women in Rural Western Kenya; A Cross-Sectional Study. PLOS Neglected Tropical Diseases, 3, e370. https://doi.org/10.1371/journal.pntd.0000370

[12] World Health Organisation (2002) Prevention and Control of Schistosomiasis and Soil Transmitted Helminthiasis. Report of a WHO Expert Committee 2002. WHO 
Technical Report Series 912.

[13] Larocque, R., Casapia, M., Gotuzzo, E. and Gyorkos, T.W. (2005) Relationship between Intensity of Soil-Transmitted Helminth Infections and Anaemia during Pregnancy. The American Journal of Tropical Medicine and Hygiene, 73, 783-789. https://doi.org/10.4269/ajtmh.2005.73.783 